\title{
Antisocial Behaviour and the Vulnerable Public
}

Stuart Waiton, Abertay University

This is the author's original manuscript, which has not been edited. The definitive, published, version of record is available from:

http://www.palgrave.com/page/detail/antisocial-behaviour-in-britain-sarah-

pickard/?K=9781137399304.

Published version (C) Palgrave Macmillan. Reproduced with permission of Palgrave Macmillan.

Waiton, S. 2014. Antisocial behaviour and the vulnerable public. In: S. Pickard, ed, Anti-social

behaviour in Britain: Victorian and contemporary perspectives. Basingstoke: Palgrave. pp.203-213. 


\title{
Antisocial Behaviour and the Vulnerable Public \\ Stuart Waiton
}

\section{Keywords}

Vulnerability, antisocial behaviour, fear, safety, diminished subjectivity

\begin{abstract}
Key to understanding the emergence of antisocial behavior legislation in the UK is the concept of diminished subjectivity, the emergence of an insecure elite guided by a precautionary principle of safety, and the construction and engagement with a universalised vulnerable public. As such this chapter attempts to explain how the demoralisation of the Cold War political framework resulted in a new relationship developing between previously political and moral subjects and the (post) modern elite. Central to this is the transformation of the robust liberal subject into a newly conceptualised vulnerable individual. Helped by the decline of moral conservatism and the collapse of political radicalism the active individual and collective were reimagined as victims of crime and vulnerable groups. Once reconceptualised in this way, the more fragmented public of the post-Cold War world, were engaged with through the emotion of fear and the therapeutic state stepped in to regulate an increasing array of behaviours, actions and speech that were previously not seen as criminal or in need of state control. The outcome is the institutionalisation of an asocial, fragile character type as the new norm for society by an insecure state that keeps us all at a safe distance from one another.
\end{abstract}

\section{Introduction}

Sociological discussions about 'late-modern' society are often confusing with regard to the nature of what is repeatedly described as our 'neo-liberal' times (Hay 2007). Not only is it difficult to find any group of individuals who would describe themselves as neo-liberal, but in policy, in law and in the nature of policing today, there is little trace of a 'liberal' sentiment (Ramsay 2012). We may live in a market society, but we also live in a therapeutic culture (Furedi 2004; Nolan 2001). At the level of culture and politics this is not a society that treats its citizens as liberal subjects, but as diminished vulnerable individuals. This is in stark contrast to the Victorians, who were passionate about the need for personal responsibility 
and autonomy (Himmelfarb1989). The rhetoric of freedom and responsibility may continue today, but they often mean something very different from anything the classical liberal John Stuart Mill (1999) proposed in the nineteenth century. Freedom, for example, since the mid1990s, has been discussed with reference to the 'freedom from fear', while responsibility is more often than not an instruction to people to 'behave', rather than something adopted by the self-willing action of independent minded individuals (Mill 1999). Central to this change has been the transformation of the ontological understanding of the individual. The Victorian ideal of the robust, free individual has been replaced by the 'ideal' of the vulnerable public - made up of dependent potential victims who need to be protected, not only from crime (or harm) but from an increasing array of behaviours.

The ideal of moral independence faced constant difficulties in the Victorian period with regards to the poor, with the conflicting need to support those in desperate need while at the same time ensuring personal responsibility was not undermined (Payne 2005: 35). There was an elitist suspicion, by some at least, that certain sections of society lacked the capacity to develop their moral independence. However this remained a contested area one often reflecting the elites own belief or disbelief, in the liberal project of the time. Charitable support was discouraged from being given to the 'undeserving', especially when the Charity Organisation Society (COS) was set up in 1869, unless there was evidence of potential moral improvement and self-reliance within the individuals and families in question. Through the process of encouraging the development of character, it was believed that 'demoralisation' would be prevented (Jordon, 1974: 26). Despite radical criticism of 'Liberal Britain' at the time, and a fervent critique of the economic and political barriers to human emancipation, for Marxists, like Frederick Engels, the belief in the human subject was not questioned (Engels 2009). Indeed, for Engels, as for Marx, there was an absolute belief in the capacity of the public to act, organise and fight for a better world.

At this time the question of crime was often discussed with reference to both a 'scientific' and/or a moral approach towards the individual. The 'residuum' was seen as being naturally inferior or morally degenerate. However, in general it was assumed that this group of 'degenerates' was relatively small compared to the majority of the population who it was assumed should and could aspire to be upstanding, sturdy and vigorous individuals.(Cullen 1996). The idea that the public in general could be classified as 'vulnerable' would make no sense to the Victorian elites. Indeed at a wider cultural and 
political level the liberal ideal of autonomous robust individualism and a belief in the importance of cultivating strength of character were widespread throughout British society regardless of political beliefs (Himmelfarb 1991).

Today, social policies and laws are not developed with this robust liberal individual in mind: We do not have a liberal or a neo-liberal culture. In many respects the opposite is the case. Rather than new initiatives to regulate behaviour reflecting a belief in the capacity of the individual they reflect an ontological approach that epitomises a sentiment of diminished subjectivity (Heartfield 2002). Consequently new laws are developed, not with the free, autonomous individual in mind, but with a new normative framework that is predicated upon the idea of our essential vulnerability, or what Peter Ramsay has described as our 'vulnerable autonomy' (Ramsay 2012).

\section{Vulnerable Autonomy}

In his legal analysis of society's preoccupation with safety, a preoccupation that emerged in the 1990s, Peter Ramsay attempts to explain how and why new laws that protect our feeling of security have emerged in the last two decades. For Ramsay these new laws have been able to develop and proliferate, despite our apparently liberal form of justice, because of the transformation in the normative sense of the human subject. Antisocial Behaviour Orders (ASBOs), he argues are novel, not because they attempt to protect our feeling of safety (something other laws have done), but because ASBOs are specifically and directly concerned with our subjective feeling of security. Unlike previous laws, ASBOs, Ramsay notes, are solely concerned with our feelings, specifically with our feeling of fear. Unlike the Public Order Act of 1986 ASBOs are not about acts we have committed, but acts we may do in the future that may create fear; with the authorities determining on our behalf what type of behaviour may cause such fear.

Under section 1(1)(a) of the Crime and Disorder Act 1998, antisocial behaviour is described as 'conduct that would, more probably than not, cause the most sensitive person actually present in the particular context to fear for their safety' (Ramsay 2012: 23, my emphasis). Consequently the ASBO can be seen as an administrative form of risk management, a risk management that aims to prevent antisocial behaviour. The ASBO, Ramsay concludes, is essentially about reassuring the public, a public that has been defined through the feelings of an imagined or constructed 'most sensitive person'. Explaining why 
hearsay evidence should be used when dealing with antisocial behaviour Lord Hutton argued that this created a fairer balance between individual rights and the demands of the community. Once again however, this is a particular type of 'idealised' community, as Lord Hutton specifies, 'the community in this case is represented by weak and vulnerable people' (Ramsay 2012: 60). The principles of law, of evidence gathering and forms of proof can be undermined because the law, as was, is no longer sufficient, no longer sufficient Ramsay suggests, because the nature of the legal subject in question has been transformed and reclassified in our more therapeutic culture, as sensitive, weak and vulnerable.

The assumption being made is that there is a reassurance gap in society that must be filled through the use of orders that regulate further the behaviour of citizens. Here we see the new framing of rights and responsibilities, where citizens are no longer simply free, but are free based on prior positive obligations centred on the necessary recognition that people and communities are fundamentally vulnerable and must be protected from fear. Once conceptualised in this way, previously defined 'nuisance' behaviour that was seen as relatively trivial and not serious enough to be dealt with by the law, or conduct that it is believed can create any level of insecurity, is transformed into a profoundly significant thing, something that undermines both individuals and communities.

Citizens need reassurance. But asks Ramsay, what sort of citizen/subject is it needs this level of reassured? The answer is that it is the vulnerable person who no longer receives sufficient protection from existing laws who now need this right to be reassured.

\section{Universalising victimhood}

Discussing the rise of the New Labour Party in the 1990s, a party that was to be in government for thirteen years, and which promoted the idea of Third Way politics, James Heartfield notes:

\footnotetext{
The Third Way connected with the electorate, not on the basis of their collective purpose, but instead playing upon their individuation and the anxieties that arose from it. The voters were no longer represented in the polity as the collective subject of the democratic process. Instead they were recognised by the state as the isolated and persecuted victims of events beyond their control (Heartfield 2002: 199).
}

Central to Heartfield's discussion of diminished subjectivity is the understanding of a transformation in politics. A transformation that saw the diminution of what C. Wright Mills 
(1968) described as an active public, and as significantly, a transformation that saw the emergence of an increasingly disconnected or liquid elite (Bauman 2000). As politicians searched for a 'Big Idea', Laïdi argued that in the post-Cold War era we had entered a World Without Meaning (Laïdi 1998): A world that lacked political imagination (Furedi 2005) or moral purpose (Lasch 1977: 187) and which resulted in the formation of a culture of fear (Furedi 1997) or what David Garland (2002) described as a culture of control.

Safety increasingly became a framework for developing policies and engaging with the public. In the 1990s everyday activities were rebranded, and safety became a framework around which institutions organised. Consequently terms like safe-play, safe-sex and community safety emerged as part of what Furedi described as a new culture of limits (Furedi 1997). Within this context, concerns about crime were extended to incorporate wider anxieties about safety and importantly, increasingly began to engage not only with crime but the (perceived) fear of it. The role of local authorities, politicians and the police incorporated a need to reduce public insecurities and so, it was believed, help to strengthen, perhaps even rebuild, communities. As Garland argues, fear 'once regarded as a localized, situational anxiety, afflicting the worst-off individuals and neighbourhoods, has come to be regarded as a major social problem and a characteristic of contemporary culture' (Garland 2002: 10).

Illustrating the way in which the public were being conceptualised and engaged with by politicians at this time, in 1997 the shadow Home Secretary Jack Straw described the fear of crime as something that essentially imprisons entire sections of society. The extent of the problem of the fear of crime, Straw believed, meant that:

Two thirds of women pensioners are scared to leave their house at night. Our pensioners are prisoners in their own homes who only want to live in peace. Surely the prisoners should be those who commit the crimes, not those who are the victims of crime. It cannot go on (Guardian 26 April 1997).

With this permanent and fundamental sense of fear, which was understood to be hovering above communities, the basis for police intervention was transformed into a more subjectively constituted defence of the public's emotional well-being. In a sense the community being engaged with was a community of vulnerable individuals, a community victimised by fear. This perceived sense of victimhood was understood to be the potential 
common bond between individuals - and the basis of state engagement and legitimation. As Garland explains:

\begin{abstract}
The symbolic figure of the victim has taken on a life of its own [and has become]...a new social fact. The victim is no longer an unfortunate citizen who has been on the receiving end of a criminal harm, and whose concerns are subsumed within the 'public interest'...The victim is now, in a certain sense, a much more representative character, whose experience is taken to be common and collective, rather than individual and atypical (Garland 2002: 11).
\end{abstract}

\title{
Diminishing subjects
}

The universalising dynamic of 'the victim' relates not simply to objective changes in society but arguably more significantly to the interpretation of the social, political and cultural changes that occurred from the 1970s. For conservatives like James Q. Wilson (the inventor of the 'broken windows' theory of crime), the new focus upon the victim of crime in the United States reflected his understanding that morality was no longer a credible force for good in society. Christian ethics and morality, he believed, had held people together but in the twentieth century (of the self) even the middle classes had abandoned this outlook and as morality declined little was left to control people's impulses (Wilson 1985). Most significantly, for Wilson there was no going back to a moral world. Pragmatism or 'realism' was needed in politics and in addressing crime in society. Consequently Wilson argued that we needed to take a 'more sober view of man', foolish aspirations needed to be abandoned and 'utopian things forgotten' (Wilson 1985: 250).

Wilson was one of the most significant conservative thinkers who first proposed the need to elevate the importance of the victim of crime. As Best notes, this had become a trend amongst right wing politicians in America at the end of the 1960s (Best 1999: 98). But this elevation of the victim must be situated within the wider pessimism of Wilson's sense of loss. It was not simply the problem of crime that led to his focus on 'the victim', but more importantly his diminished sense of the moral capacity of 'man' and society.

Similarly, in the UK in the 1980s, it was the loss of belief of some of those on the left that led to the emergence of left realism and to a similar elevation of the victim and indeed the construction of entire groups of people as 'vulnerable'

In the UK, the prioritisation and representation of the victim emerged most fervently within the feminist writing of the 1970s and 80s with the 'discovery' of violence and abuse against women and children (Jenkins 1992: 231). Despite often contradictory evidence of the 
significance and even the extent of the victimisation under study, this approach had an underlying and in-built acceptance of the vulnerability of those people being studied. For example Hartless notes with 'surprise' that, of the young women who said they had experienced sexual harassment of some kind, 'only $8 \% . .$. said they had been 'very scared" (1995: 119). Surprise at any level of robustness and at the ability of 'vulnerable' individuals to cope with unpleasant experiences was coupled with a trend to interpret any evidence of fear as a product of harassment. Pain, in her analysis of fear amongst elderly women, raises the question of why older men fear crime more than young men. Despite the myriad possible reasons including physical frailty, social isolation or a sense of powerlessness and estrangement from society which could be the cause, Pain speculates that perhaps it is due to their vulnerability to harassment, 'especially in very old age, to abuse from carers inside or outside the immediate family' (Pain 1995: 595).

Whereas previously radicals had attempted to challenge the official statistics on crime and deny the 'social problem' of crime, increasingly this feminist criminology reversed this approach and attempted to prove that crime, harassment, and what would later by called 'antisocial behaviour' was even more of a problem than was officially accepted. Being a 'victim' of crime and antisocial behaviour was no longer simply a passing event, but became something that defined the lives and identity of 'vulnerable groups'.

In the 1980s feminist and left realist concerns about the impact of crime on individuals and society drew closer to the official criminological approach at the time - especially with the common use of victim statistics. 'Establishment' criminology had however undergone its own transformation during this period moving from a positivist belief in society's capacity to overcome the problem of crime to an 'administrative criminology' (Young 1988: 174). This administrative criminology, associated with Wilson's (1985) approach to crime, was a more pragmatic method of dealing with the effects of it. Despite the political nature of much of the feminist and particularly the left realists approach to crime, the common bond that had brought them and the official criminologist closer to one another was a diminished belief in moral or political and social possibilities to resolve the problem of crime. With a greater pessimism about society and a greater sense of distance from social change and outcomes, radical and conservative thinkers became more preoccupied with the plight of the victim. The public, or at least substantial sections of it were now increasingly conceptualised as being what Stanko described as, 'universally vulnerable' (Pain 1995: 596). 
The significance of crime and behaviour for New Labour in the 1990s was assisted by the work of feminist and new realist thinkers of the left in the 1980s, who helped to formulate an understanding of the public as vulnerable. In Philip Jenkins' analysis of Moral Panics in Contemporary Great Britain, in which he analyses the emergence of panics around child abuse in the UK, he notes the significance of feminist as claimsmakers:

From the mid-1970s on, there evolved in Britain a strong feminist movement, which had had an enormous impact on many aspects of society and politics...[f]eminist ideas soon prevailed in radical and left-wing journals...and were commonly expressed in liberal newspapers like the Guardian...[and] by the mid-1980s, fifty local authorities had women's committees (Jenkins 1992: 35-6).

This form of feminism, as Jenkins notes, had a substantial impact upon politics in the UK - as did the left realists, led by Jock Young, who, like these feminists, had become disillusioned with the idealist beliefs of the radical left. Crime for these left realists needed to be taken seriously and victims needed to be placed at the centre of concern for criminologists and the state. As Matthews and Young argued - expressing sentiments that were later to be echoed by the likes of New Labour's David Blunkett:

Crime is of importance because unchecked it divides the working class community and is materially and morally the basis of disorganisation: the loss of political control. It is also a potential unifier - a realistic issue, amongst others, for recreating community (Matthews and Young 1986: 29).

Developing out of the radical framework of the early 1970s, a number of feminist and realist criminologists became disillusioned with the fight for political and social change and, rather than challenging the issue of crime as an elite concern or method of social control, increasingly identified crime as a major issue, particularly for the poor, women and blacks who were now understood as being 'victims of crime' (Jones et al 1986). Discussing the shift in Labour councils from radicalism to realism Young noted that:

The recent history of radical criminology in Britain has involved a rising influence of feminist and antiracist ideas and an encasement of left wing Labour administrations in the majority of the inner city Town Halls. An initial ultra-leftism has been tempered and often transformed by a prevalent realism in the wake of the third consecutive defeat of the Labour Party on the national level and severe defeats with regards to "rate capping" in terms of local politics. The need to encompass issues, which had a widespread support amongst the electorate, rather than indulge in marginal or "gesture" politics included the attempt to recapture the issue of law and order from the right (Young 1988: 172). 
It was sections of the left who, with the support of their victim surveys, both discovered and advocated on behalf of women, blacks and the poor as victims of crime, the problem of fragmented communities being located within the prism of crime, antisocial behaviour and the fear of crime. From this perspective the tendency was for Young and his co-authors both to exaggerate the significance of crime and to generalise an understanding of the public as fundamentally vulnerable - within the narrow parameters of crime and antisocial behaviour. In particular, previously radical political issues were transformed into victim claims for newly conceptualised 'vulnerable groups', incorporating black people, women and homosexuals into this new and diminished caricature. In the demoralised and poverty stricken inner-city areas of London, like Islington, where crime rates were five times the national average, the equally demoralised realists concluded that it was the problem of crime that 'shaped their lives' (Jones et al 1986: 201). While correctly noting that crime was not a fantasy for the people of Islington, these realists noted that a third of the women of the area avoided going out after dark, concluding that this represented a, 'virtual curfew of the female population' (1986: 201). This misrepresentation of one third of women being transformed into the entire female population reflected not simply an exaggeration, but a newly developing conceptualisation of the public more generally as vulnerable - something which was to become more central to the Labour Party's understanding of social problems in the 1990s and would help to transform the relationship between citizen and state.

\section{The rise of antisocial behaviour}

By the turn of the millennium the Labour Party in Britain had made antisocial behaviour into a major political issue. Labour MP Frank Field went so far as to describe the problem of antisocial behaviour as the 'newest horseman of the apocalypse' (Field 2003: 64). In 2002 prime minister Tony Blair used the Queen's Speech - where the priorities for the government are set out - to explain that antisocial behaviour - and specifically vandalism, graffiti and fly-tipping was, 'probably the biggest immediate issue for people in the country' (Guardian 1 November 2002).

Looking at past newspaper articles discussing the problem of 'antisocial behaviour' it is noticeable that, for example in the Guardian, there were only one or two stories a year in the 1980s that mentioned antisocial behaviour. This contrasts with 2006 when then there 
were over 600 articles in the Guardian alone discussing antisocial behaviour: There were over 17,000 such articles in all UK newspapers in this year.

The term antisocial behaviour has existed for a long time, but in the 1990s it became a specifically political terms connecting the everyday nuisance behaviour of people with a wider sense of disorder and social breakdown. The term itself grouped together a number of relatively minor forms of bad behaviour, collectivising them in a 'broken windows' type representation of the collapse of community. Interestingly, when looking at the newspaper articles about antisocial behaviour it is noticeable that in the mid-1990s it was promoted as a significant problem with reference to crime, thus the often quoted problem of 'crime and antisocial behaviour' was how the issue was elevated as a problem. By the end of the decade however the problem of anti-social behaviour was the problem in and of itself, no longer needing the crutch of crime to give it significance. And as we have seen, for Labour politicians and the prime minister it became an apocalyptic problem - the biggest immediate issue facing the people of Britain.

For Labour party promoters of ASBOs, their focus on antisocial behaviour was portrayed as a new way to rebuild communities. In 2004 the then Home Secretary David Blunkett explained the government's approach to civic republicanism, arguing that, 'People say that actually feeling safe to walk down the street, is the first and primary goal that they want us to achieve. That way, they'll come out to public meetings, they'll go down to their local school, they'll join in in being part of the solution' (Cummings 2005: 6).

For Blunkett, fear, often generated by antisocial behaviour, was undermining communities and overcoming fear, would recreate an active political public. However, fear in communities, to the extent that it can be taken at face value, is often generated by far more than misbehaving youngsters and 'neighbours from hell'. As Elizabeth Burney notes, 'poor people do suffer more from crime and disorder but they also have more things to worry about and are more likely to feel things are out of control'. Fear of antisocial behaviour, Burney believes, can be seen as simply part of a wider culture of fear, or of risk consciousness.

Risk consciousness besets modern society and anti-social behaviour is only one among many of the issues which seize public attention. Pollution, paedophiles, food scares, medical errors and many more threaten our peace of mind as ever-present dangers which from time to time throw up peaks of alarm triggered by fresh events or 'expert' reports (Burney 2005: 11). 
At the risk of being one sided, the suggestion being made here is that it is not antisocial behaviour that creates fear - but rather, fear became expressed through the issue of antisocial behaviour.

The criminalisation of behaviour that was previously not seen as worthy of legal sanction has developed alongside the growing importance of the 'victim' within the criminal justice system. With the growth in legislation and initiatives to deal with antisocial behaviour an ever wider net has been cast that has helped to redefine more things as being 'antisocial' and to equally see more people as victims of this behaviour. What is seen as being harmful to people has expanded - as has the government's attempt to prevent harm happening.

For some the growing concern with harmful behaviour is justified and relates to the changing form of behaviour itself. Stuart Jeffries for example argues, 'That growing vulgarisation points up a problem for Mill's principle - what one person believes causes harm or thinks intolerable will be very different from another. But surely vulgarity and rudeness harm others and steadily make our culture uncivilised? Mill's principle needs to be recast for a new age' (Guardian 19 September 2005). Why Mill's principles need to be recast is unclear. Mill and those of his generation did not accept vulgarity and rudeness - but they did expect individuals to be able to deal with these issues without the use of the state and the law. What Jeffries approach represents is perhaps less the growing problem of behaviour than of a growing fragility within society and an increasing reliance on the state to resolve problems that individuals were previously expected to be able to deal with.

Indeed since the emergence of ASBOs and legislation to deal with antisocial behaviour was first introduced society has moved 'forward', and today with legislation dealing with hate crime, singing at football matches and increasingly with the regulation of what is 'said' on the internet, on Facebook and Twitter in particular, we have moved, as philosopher Joel Feinberg has argued, 'from the harm principle to the offence principle' (Cohen 2012).

The reason for this shift and for the emergence of antisocial behaviour as a major political issue is in large part due to the dialectical relationship between the diminishing sense of moral and political purpose in Western society, and the construction of the vulnerable victim - the powerless 'subject'. With a diminished sense of political possibilities, politics has increasingly become about the micro-management of society and the increasing use of law and regulations to enforce correct forms of behaviour, with safety being elevated 
as a framework for policy developments and fear being the key emotion that is recognised and engaged with. Simultaneously the individual has diminished in the mind's-eye of the elite, and new initiatives and forms of policing have developed with the thin skinned, chronically offended person as the representative character of (post) modern Britain. The community in this case, as Lord Hutton outlined above, consequently is represented by weak and vulnerable people' (Ramsay 2012: 60). Entire populations of people are imagined to be 'vulnerable groups' and the 'most sensitive person' becomes emblematic, a newly framed diminished individual around which experts and politicians orient themselves. Essentially what we are witnessing is the replacement of J.S. Mill's liberal individual with the newly construction vulnerable person and group.

In Slavoj Žižek's Violence he discusses a new norm developing in Western society, to 'fear thy neighbour as thyself'. Discussing the transformation of the meaning of tolerance, from a Millsian idea of free speech and the importance of tolerating different ideas, to one where tolerance means respect, not being offensive and indeed the criminalisation of words and behaviour. He argues:

My duty to be tolerant towards the Other effectively means that I should not get too close to him, intrude on his space. In other words, I should respect his intolerance of my over-proximity. What increasingly emerges as the central human right in late-capitalist society is the right not to be harassed, which is a right to be kept at a safe distance from others (Žižek 2009).

Tragically, despite its pretentions to the contrary, antisocial behaviour legislation is helping to enforce Žižek's asocial society, where connections between people are undermined by ever increasing initiatives to protect our 'right' to be protected from everyone around us. 


\section{Bibliography}

Bauman, Z. (2000) Liquid Modernity. Cambridge: Polity Press.

Best, J. (1999) Random Violence: How We Talk About New Crimes and New Victims. Berkley: University of California Press.

Burney, E, (2005) Making People Behave: Anti-social Behaviour, Politics and Policy. Devon: Willan.

Cohen, N. (2012) 'We only pretend to defend free speech', Standpoint, January/February edition.

Cullen, J. (1996) 'The Return of the Residuum'. In L. Revell and J. Heartfield (eds), A Moral Impasse: The End of Capitalist Triumphalism. London: Junius.

Cummings, D. (2005) in Craig O'Malley and Stuart Waiton, Who's Antisocial: The Politics of Antisocial Behaviour. London: Academy of Ideas.

Engels, F. (2009) Socialism, Utopian and Scientific. Gloucester: Dodo Press.

Field, F. (2003) Neighbours from Hell: The Politics of Behaviour. London: Politico's.

Furedi, F. (1997) Culture of Fear: Risk-Taking and the Morality of Low Expectations. London: Cassell.

Furedi, F. (2004) Therapy Culture: Cultivating vulnerability in an uncertain age. London: Routledge.

Furedi, F. (2005) The Politics of Fear: Beyond Left and Right. London: Continuum.

Garland, D. (2002) The Culture of Control: Crime and Disorder in Contemporary Society. Oxford: Oxford University Press.

Hartless, J., Ditton, J., Nair, G. and Phillips, S. (1995) 'More sinned against than sinned'. British Journal of Criminology, Vol. 35, No. 1, pp. 114-133.

Hay, C. (2007) Why We Hate Politics. Cambridge: Polity.

Heartfield, J. (2002) The 'Death of the Subject' Explained. Sheffield: Sheffield Hallam University Press.

Himmelfarb, G. (1989) Marriage and Morals among the Victorians. London: I. B. Tauris and Co Ltd.

Himmelfarb, G. (1991) Poverty and Compassion: The Moral Imagination of the Late Victorians. New York: Alfred Knopf.

Jenkins, P. (1992) Intimate Enemies: Moral Panics in Contemporary Great Britain. New York: Walter de Gruyter.

Jones T., Maclean, B. and Young, J. (1986) The Islington Crime Survey. Aldershot: Gower.

Jordon, P. (1974) Poor Parents: Social Policy and the 'cycle of deprivation'. London: Routledge.

Laïdi, Z. (1998) A World Without Meaning. London: Routledge.

Lasch, C. (1977) Haven in a Heartless World. New York: Basic Books.

Matthews, R. and Young, J. (1986) Confronting Crime. London: Sage.

Mill, J.S. (1999) On Liberty. Oxford: Oxford University Press. (first published in 1856).

Mills, C. W. (1968) Power Politics and People. New York: Ballantine.

Nolan, J. (2001) Reinventing Justice: The American Drug Court Movement. New Jersey: Princeton University Press.

Pain, R. (1995) 'Elderly Women and Fear of Violent Crime: The Least Likely Victims? The British Journal of Criminology, Vol. 35, No. 4, pp. 584-598.

Payne, M. (2005) The Origins of Social Work. Hampshire: Palgrave Macmillan. 
Ramsay, P (2012) The Insecure State: Vulnerable Autonomy and the Right to Security in the Criminal Law. Oxford: Oxford University Press.

Wilson, J. Q. (1985) Thinking about Crime. New York: Vintage Books.

Young, J. (1988) 'Radical Criminology in Britain: The Emergence of a Competing Paradigm'. British Journal of Criminology, Vol.28, No. 2, pp. 159-183.

Žižek, S. (2009) Violence. London: Profile Books. 
